\title{
Joining Ceramics to Metals by Abnormal Glow Discharge Plasma
}

\author{
アブノーマルグロー放電プラズマによるセラミックと金属の接合 \\ Yao-Wen WANG, Peng-Sheng ZHAO* and Yong-Qing ZHANG* \\ School of Electrical and Electronic Engineering, South Spine, Block S1-B4b-06, Nanyang Technological University, Singapore 639798 \\ *MSE Department, Taiyuan University of Techchnology, Taiyuan 030024, China
}

\begin{abstract}
A novel joining technique of ceramics to metals is presented, in which depositing Ti on ceramics with arc-added glow discharge is used as a prior metallizing technique and then brazing the ceramics to metals by abnormal glow discharge is carried out. The heating temperature of the base metals is easily controlled by varying the operating voltage and barometric pressure. The ions beam from the glow discharge anode is efficiently able to sputterclean the surfaces of the base materials, which thereby improves better Ti-deposited adhesion on the ceramics and the wetting and spreading properties of the filler metal. The thickness of the Ti-deposited layer is readily adjusted in terms of the actual requirement. The vacuum pressure during brazing can be up to $5 \mathrm{~Pa}$. The cost and duration of the glow discharge plasma brazing are reduced as compared with the traditional vacuum brazing process. The joining technique developed holds potential for industrial applications leading to high product quality.

[Received December 1, 2004; Accepted March 23, 2005]
\end{abstract}

Key-words : Abnormal glow discharge, Electric arc depositing, Joining, $\mathrm{Si}_{3} \mathrm{~N}_{4}$

1. Introduction

Ceramics have fascinating characteristics as structural and electronic materials due to their excellent mechanical and thermal properties such as high temperature strength, low density, high hardness, low thermal expansion, and good corrosion resistive properties. With the development of novel techniques for producing ceramics, more and more interest has been focused on their use in advanced engineering designs. ${ }^{1)}$ However, because of their brittle nature, poor formability and high manufacturing cost, it is highly desirable to fabricate metal-ceramic joints in the systems and the successful performance of such systems depends on the quality and reliability of the ceramic-to-metal joints. Therefore, searching for the proper joining processes for the fabrication of metal-ceramic joints for the various applications attracts many researchers' attentions in recent years. ${ }^{2)-4)}$

Of the joining processes of ceramics to metals or different ceramics, indirect vacuum brazing, in which the ceramic surfaces are metallized prior to brazing with conventional filler metals, has found wide applications in many industrial fields. ${ }^{5)}{ }^{-7}$ In reference, ${ }^{7)}$ the alumina ceramic surface was prepared by pulsed plasma beams combined with arc PVD treatment (working gas was oxygen) and the subsequent brazing process was in a normal vacuum furnace $\left(10^{-4} \mathrm{~Pa}\right.$ initial pressure and $2 \times 10^{-3} \mathrm{~Pa}$ pressure during the peak brazing temperature). Traditionally, because the ceramic-metal brazing joints are achieved at a vacuum pressure of 1.0-5.0 $\times 10^{-3}$ $\mathrm{Pa}$ or more lower, mechanical vacuum and oil diffusion pumps are used at the same time to evacuate the vessel, ${ }^{8)-10)}$ which may result in high vapor pressure elements evaporation during especially high temperature. The vacuum brazing cycles are also extended because of the longer vacuum-evacuating time. Moreover, the traditional vacuum brazing employs resistance radiation heating (heating produced by resistance wires through radiation), and the heating efficient is low because there is nearly no conduction or convection inside the chamber.

In this paper, a novel method is described, in which depositing $\mathrm{Ti}$ on silicon nitride ceramics with arc-added glow discharge plasma ${ }^{11), 12)}$ is used as a prior metallizing process and then brazing ceramics to metals with abnormal glow discharge plasma $^{13), 14)}$ is carried out. The ions beam is efficiently able to sputter-clean the surface of the base materials and filler metal, and directly heat the base material on the glow discharge cathode. During glow discharge plasma brazing, the vacuum in the furnace requires a minimum pressure of $5 \mathrm{~Pa}$ or higher and one mechanical pump can meet the process demands. The process characteristics and the relevant mechanism of the new brazing technology are investigated. Brazing $\mathrm{Si}_{3} \mathrm{~N}_{4}$ ceramic to carbon steel is performed. The microstructure and mechanical properties of the glow discharge brazing joints are evaluated.

\section{Experimental details}

The experiments were carried out inside an arc-added glow discharge furnace (as shown in Fig. 1). Ti metal, used as the arc cathode, is connected to the negative output of the

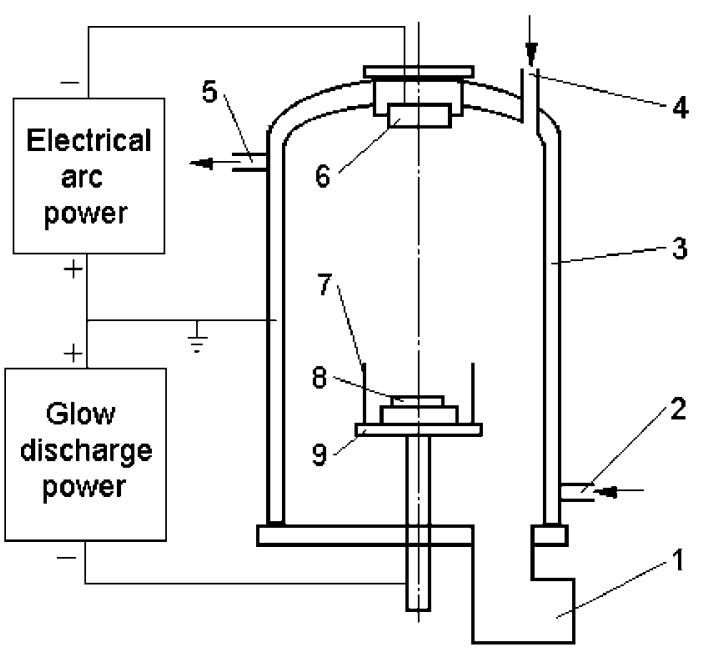

Fig. 1. Schematic diagram of experimental setup: 1, Vacuum evacuating system; 2, Cooling water inlet; 3, Vacuum chamber wall; 4, Argon inlet; 5, Cooling water outlet; 6, Arc Ti cathode; 7, Additional cathode; 8 , Base materials; 9, Glow discharge cathode. 


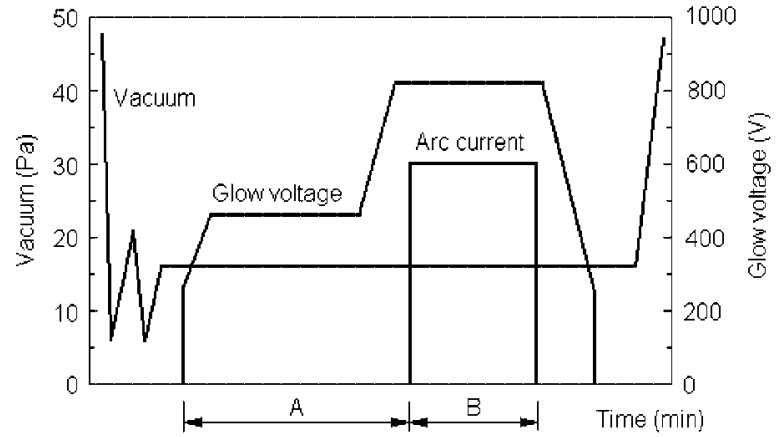

Fig. 2. Glow discharge depositing or brazing process: A, Sputter-cleaning; B, Depositing (arc was switched on) or brazing (arc was not switched on).

arc power source, and mounted in the top of the arc-added glow discharge furnace. An additional cathode (see No. 7 in Fig. 1) is placed at the cathode support so that the sample heating temperature is even. The additional cathode is made of metal sheet in shape of a circular wall and enclosed the base metals. The base materials are silicon nitride ceramics $\mathrm{Si}_{3} \mathrm{~N}_{4}$ $(12 \times 10 \times 12 \mathrm{~mm})$ and carbon steel $(30 \times 25 \times 2 \mathrm{~mm})$. The filler metal is 72 mass $\% \mathrm{Ag}-28$ mass $\% \mathrm{Cu}$ alloy $\left(780^{\circ} \mathrm{C}\right) . \mathrm{SEM}$ observed the microstructure of the cross section of the brazing joints. EDX detected the diffusion of the joint elements.

The schematic processes of the depositing and subsequent brazing are shown in Fig. 2. As can be seen, there are two main portions for each process: sputter-cleaning and depositing (the arc was switched on) for the depositing process, and sputter-cleaning and brazing (the arc was not switched on) for the brazing process. Firstly the metallizing or depositing process for ceramics was carried out in the furnace. The ceramic was cleaned with acetone in an ultrasonic cleaner for about $15 \mathrm{~min}$, and then introduced into the arc-added glow discharge furnace. The vessel was evacuated to about $6 \mathrm{~Pa}$ and then filled with argon to about $20-30 \mathrm{~Pa}$ repeatedly for 2-3 times to purify the vacuum atmosphere. The abnormal glow discharge was initiated. The glow discharge voltage was held at $400-500 \mathrm{~V}$ for about 5-10 min so as to sputter-clean the surfaces of the base materials. After that, the glow voltage was increased to $750-850 \mathrm{~V}$, the arc was switched on and hence Ti was deposited on the ceramic surface. About 10-15 min after, the arc was extinguished and the glow voltage was reduced step by step. The samples were taken out of the chamber. In the next step the brazing process was conducted in the furnace. After the carbon steel and the filler metal were cleaned with acetone the ceramic was placed on the carbon steel. The filler metal was placed around the brazing joint and on the carbon steel. The samples were introduced into the furnace again. As shown in Fig. 2, the furnace evacuated and glow discharge were initiated. After that, brazing was performed for about 10-14 min. Thus, a brazing joint was achieved.

\section{Results and discussion}

\subsection{Heating temperature control of the base materials}

During the abnormal glow discharge plasma, the cathode spots cover the whole cathode surface. The ions beam acts on the cathode surface and heats it. On the basis of gas discharge theory and experiment investigation, the cathode temperature is given by:

$$
T \propto t P^{2} V^{2}
$$

Table 1. Relationship between the Depositing Thickness and the Depositing Time

\begin{tabular}{ccccccccc}
\hline Time $(\mathrm{min})$ & 2 & 4 & 6 & 8 & 10 & 12 & 16 & 20 \\
\hline $\begin{array}{c}\text { Thickness } \\
(\mu \mathrm{m})\end{array}$ & 3.4 & 4.3 & 5.8 & 7.8 & 10.5 & 13.3 & 17.2 & 22.0 \\
\hline
\end{tabular}

where $T$ is the cathode temperature, ${ }^{\circ} \mathrm{C} ; t$ is the heating time, $\min ; P$ is operating barometric pressure, $\mathrm{Pa} ; V$ is the operating voltage of the abnormal glow discharge plasma, $V$. As can be seen from the equation, when the other conditions are fixed, the heating temperature of the glow discharge cathode materials is proportional to the product of heating time, the square of glow discharge voltage, and the square of operating barometric pressure. With the increase of the glow discharge voltage and the vacuum pressure, the temperature of the brazing members goes up rapidly. Therefore, the brazing temperature of the workpiece can be easily adjusted by means of operating barometric pressure and glow discharge voltage.

The additional cathode (see No. 7 in Fig. 1) is used at the cathode. The glow discharge takes place inside the metal wall due to hollow cathode effect, and heat is distributed more evenly and dissipated in smaller amounts. Thus, the the cracking of the ceramics caused by uneven heating, which may in turn influence the quality of the brazing seam, can be avoided to some extent.

Therefore, the glow discharge plasma is an efficient brazing heat source. During abnormal glow discharge depositing and brazing, the cathode temperature and its distribution can easily be adjusted so as to meet the demands of the joining processes.

\subsection{Control of deposited layer thickness}

It is shown from the experiments that the arc current and the depositing time have an important influence on the thickness of the deposited layer.

The surface temperature of the arc Ti cathode is proportional to the arc current. Because the arc cathode spots have high current density $\left(10^{6}-10^{8} \mathrm{~A} / \mathrm{cm}^{2}\right)$, high temperature (about $3500-5000 \mathrm{~K}$ ), and small size (about $10^{-4} \mathrm{~cm}$ in diameter), ${ }^{12)}$ the material in the spots rapidly melts, evaporates and ionizes. The particles from the arc cathode surface move to the substrates on the action of the electric field of the glow discharge. With the rising of the arc current, the number of these particles increases, the deposited particles per unit time increase, and hence thickness of the deposited layer per unit time becomes large. However, if the arc current is too high, the arc cathode may be deformed and even damaged. Usually, the arc current is selected in the range of $35-50 \mathrm{~A}$.

The depositing time is another major factor affecting the thickness of the deposited layer. The longer the time is, the thicker the deposited layer. When the glow discharge voltage is $750 \mathrm{~V}$, the working pressure $15 \mathrm{~Pa}$, and the arc current $40 \mathrm{~A}$, the relationship between the depositing thickness and time is shown in Table 1. The depositing thickness is approximately proportional to the depositing time. Under the experimental conditions, the depositing time of $10-15 \mathrm{~min}$ is used. If the depositing time is shorter, the Ti-ceramic reaction layer is too thin. If the time is longer, the residual stress level is increased, which may have an unfavorable effect on the joint strength.

\subsection{Microstructure of brazing joints}

The SEM micrograph of a brazed joint is shown in Fig. 3. As can be seen from the figure, the filler metal fills the brazed gap very well, and the microstructure of the joint is dense and homogeneous. The Ti-deposited layer, approximately 12-14 


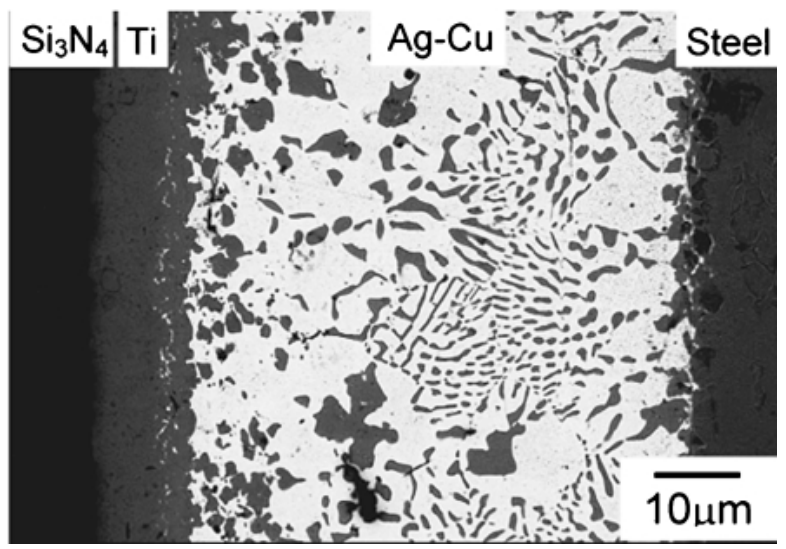

Fig. 3. SEM micrograph showing the interfacial region of a $\mathrm{Si}_{3} \mathrm{~N}_{4} /$ carbon-steel brazed joint: the Ti-deposited layer is the dark-gray region (pointed out) between the ceramic and the bright $\mathrm{Ag}-\mathrm{Cu}$ eutectic (Ti-deposited time is $12 \mathrm{~min}$, brazing time $12 \mathrm{~min}$ and brazing temperature $830^{\circ} \mathrm{C}$ ).

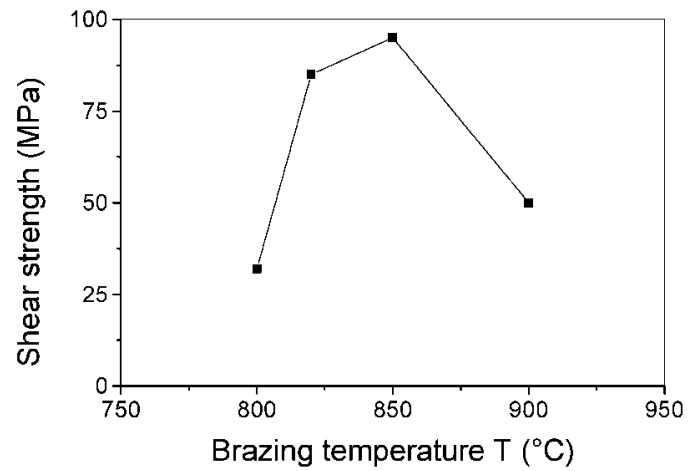

Fig. 4. Effect of brazing temperature on shear strength of $\mathrm{Si}_{3} \mathrm{~N}_{4} /$ carbon-steel joints ( $\mathrm{Ti}$-deposited time is $12 \mathrm{~min}$ and brazing time 12 $\min )$.

$\mu$ m thick, is dark-gray and between the $\mathrm{Si}_{3} \mathrm{~N}_{4}$ and the $\mathrm{Ag}-\mathrm{Cu}$ eutectic structure. Furthermore, because of $\mathrm{Ti}$ diffusion in filler metal, the braze seam is irregular on the Ti-deposited side. Another microstructure feature observed in the joints is a thin ribbonlike Ti-rich phase that often delineates the $\mathrm{Ti} / \mathrm{eu}-$ tectic boundary, and EDX analysis indicates the presence of $\mathrm{Cu}$ in this phase. The Ti-rich phase, the shape of which is irregular spheroidal, is also observed in the bright $\mathrm{Ag}-\mathrm{Cu}$ eutectic as depicted in Fig. 3.

\subsection{Influence of brazing parameters on joint strength}

The shear strength of indirectly brazed $\mathrm{Si}_{3} \mathrm{~N}_{4} /$ carbon-steel joints has been plotted versus the brazing temperature in Fig. 4. As can be seen from the figure, the strength tends to increase with the elevation of the brazing temperature until a maximum level is reached (at $850^{\circ} \mathrm{C}$ ), which is consistent with a continuous growth of the reaction layer with increasing temperature. However, beyond the temperature the joint strength is rapidly reduced. This reduction may be caused by extensive interaction between the ceramics and the Ti-deposited layer, i.e. rapid growth of the reaction layer. In addition, an increase in the brazing temperature may result in an associated increase in the residual stress level.

As experienced with temperature, the strength of $\mathrm{Si}_{3} \mathrm{~N}_{4} /$ carbon-steel joints passes through a maximum with increasing

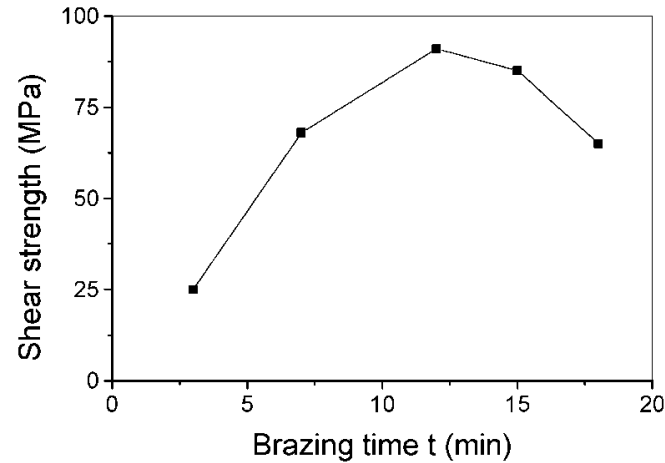

Fig. 5. Effect of brazing time on shear strength of $\mathrm{Si}_{3} \mathrm{~N}_{4} /$ carbon-steel joints (Ti-deposited time is $12 \mathrm{~min}$ and brazing temperature $\left.830^{\circ} \mathrm{C}\right)$.

brazing time. The observation is illustrated in Fig. 5. This is because the reaction layer between the ceramics and Tideposited layer gradually becomes thick with the extension of the brazing time. It is shown from experiments that the optimum brazing time is about 10-14 min under the experimental conditions.

\subsection{Discussion}

Filler metal wetting is the ability of the molten brazing filler metal to adhere to the surface of the substrates in the solid state and, when cooled below its solidus temperature, to make a strong bond to the parent materials. During joining process, the presence of adsorbed molecules on the surface of the parent materials markedly reduces the surface energy, which increases the contact angle and retards filler metal wetting. Therefore, clean surfaces and their maintenance in joining process is important. In the glow discharge plasma, the ions beam can efficiently sputter-clean the surface of the base materials and remove absorbed atoms, such as oxide films and impurities, by means of the ions bombardment effect taking place on the whole course. For example, the SEM micrograph analysis of a carbon-steel sample indicated that there are distinct rolling strips on the surface of the sample before introducing into the furnace; and however the rolling stripes have nearly disappeared and the surface is uneven After sputter-cleaned for about $15 \mathrm{~min}$ in the glow discharge vacuum furnace. As a result, the conditions of the filler metal wetting and spreading on the surface of the base materials can be greatly improved during the glow discharge plasma brazing. Fluxless brazing in glow discharge plasma can be achieved at a much higher pressure (at a level of $10 \mathrm{~Pa}$ ) than traditional vacuum brazing (range from the order of $10^{-2}$ to $10^{-3} \mathrm{~Pa}$ ). The cost and duration of the glow discharge plasma brazing are reduced as compared with traditional vacuum brazing processes, in which an expensive two-stage air evacuating system is needed and the evacuating time is also much longer.

In addition, during depositing, the ions bombardment may knock in and sputter off atoms in the ceramic surface or growing coating, filling the microscopic pores on the surface of the ceramics or the pores which would normally form during depositing. Atoms arriving at the surface may be ionized or electronically excited by the ions beam, making them much more chemically active. Consequently, the interface reaction and the bonding strength between the Ti-deposited layer and ceramic are facilitated, so that the subsequently brazing time can be shortened. The arc-added glow discharge technique developed has wide application prospects in materials joining industries. 


\section{Conclusions}

(1) The glow discharge plasma can directly heat the cathode surface, and is an efficient brazing heat source. The brazing temperature is easily controlled by the means of glow discharge voltage and operating barometric pressure, and the temperature distribution can also be adjusted by using an additional cathode.

(2) The ions beam efficiently sputter-cleans the surface of the base materials and filler metal, which promotes better depositing adhesion and improves the wetting and spreading conditions of the filler metal. The thickness of the Ti-deposited layer is readily adjusted in terms of the actual requirement.

(3) The vacuum pressure can be up to $5 \mathrm{~Pa}$ or higher, which is much higher than the vacuum pressure of $1.0-5.0 \times$ $10^{-3} \mathrm{~Pa}$ for the traditional vacuum joining processes. The cost and duration of the glow discharge plasma brazing are reduced as compared with the traditional vacuum brazing process.

The joining technique developed holds promise for industrial applications leading to high product quality.

Acknowledge The authors wish to thank a reviewer for his/ her comments and suggestions which led to several improvements of this paper.

\section{References}

1) Park, J. W., Mendez, P. F. and Eagar, T. W., Acta Materialia, Vol. 50, pp. 883-899 (2002).
2) Chaumat, G., Drevet, B. and Vernier, L., J. Eur. Ceram. Soc., Vol. 17, pp. 1925-1927 (1997).

3) Elsawy, A. H. and Fahmy, M. F., J. Mater. Proce. Tech., Vol. 77, pp. 266-272 (1998).

4) Peteves, S. D., Ceramics International, Vol. 22, pp. 527-533 (1996).

5) Foley, A. G., Industrial Ceramics, Vol. 19, pp. 193-195 (1999).

6) Matsuo, Y. I. and Taniguchi, M. M., Industrial Ceramics, Vol. 19, pp. 203-207 (1999).

7) Piekoszewski, J., Krajewski, A., Prokert, F., Senkara, J., Stanislawski, J., Walis, L., Werner, Z. and Wlosinski, W., Vacuum, Vol. 70, pp. 307-312 (2003).

8) Wilkenhoener, R., Buchkremer, H. P. and Stoever, D., J. Mater. Sci., Vol. 36, pp. 1783-1788 (2001).

9) Ljungberg, L. Y., British Ceramic Transactions, Vol. 100, pp. 218-228 (2001).

10) Passerone, A. and Muolo, M. L., Materials and Manufacturing Processes, Vol. 15, pp. 631-648 (2000).

11) Pan, J. D., Fan, B. H. and Xu, Z., Technology and equipment of ions metallic cementation by using glow discharge plasma with arc. China Patent 90103841, 6 June 1990.

12) Pan, J. D., Fan, B. H. and Li, C. M., Acta metallurgica sinica, Vol. 29, pp. B424-B427 (1993).

13) $\mathrm{Xu}, \mathrm{Z}$., Method and apparatus for introducing normally solid materials into substrate surfaces. USA Patent 4520268, 28 May 1985.

14) Xu, Z., Du, S. F. and Fan, B. H., Alloying furnace with doublelayer glow discharge plasma. China Patent 87104626, 1 July 1987. 